\title{
An accessibility graph-based model to optimize tsunami evacuation sites and routes in Martinique, France
}

\author{
M. Péroche ${ }^{1}$, F. Leone ${ }^{1}$, and R. Gutton ${ }^{2}$ \\ ${ }^{1}$ UMR GRED (UPV Montpellier 3/IRD), Centre IRD de Montpellier - BP 6450134394 Montpellier cedex 5, France \\ ${ }^{2}$ UMR Espace-Dev, Centre IRD de Martinique - BP 800697259 Fort-de-France cedex, France \\ Correspondence to: M. Péroche (mathieu.peroche@gmail.com)
}

Received: 6 May 2013 - Revised: 4 December 2013 - Accepted: 5 December 2013 - Published: 23 January 2014

\begin{abstract}
The risk of tsunami threatens the whole Caribbean coastline especially the Lesser Antilles. The first available models of tsunami propagation estimate that the travel time from the closest seismic sources would only take few minutes to impact the Martinique Island. Considering this threat, the most effective measure is a planned and organized evacuation of the coastal population. This requires an efficient regional warning system, estimation of the maximum expected tsunami flood height, preparation of the population to evacuate, and drawing up of local and regional emergency plans. In order to produce an efficient evacuation plan, we have to assess the number of people at risk, the potential evacuation routes, the safe areas and the available time to evacuate. However, this essential information is still lacking in the French West Indies emergency plans. This paper proposes a model of tsunami evacuation sites accessibility for Martinique directly addressed to decision makers. It is based on a population database at a local scale, the development of connected graphs of roads, the identification of potential safe areas and the velocity setting for pedestrians. Evacuation routes are calculated using the Dijkstra's algorithm which gives the shortest path between areas at risk and designated evacuation sites. The first results allow us to map the theoretical times and routes to keep the exposed population safe and to compare these results with a tsunami travel time scenario.
\end{abstract}

\section{Introduction}

The tsunami hazard threatens the whole Caribbean coastline, with a higher propensity for windward coasts directly exposed to the effects of earthquakes in the subduction zone of the Lesser Antilles. Tsunamigenic earthquakes related to the tectonics of the back arc system are also likely to occur (e.g. Saintes earthquakes and tsunami in 2004, Le Friant et al., 2008). The occurrence of this event in this particular geosystem must be considered because of the proximity of the possible sources to highly populated coastal areas.

During the last 500 years, nearly 300 validated and unverified events of tsunami run-ups had been identified in this area (NGDC/WDS, accessed January 2013) ${ }^{1}$. Over the same period, according to Accary and Roger (2010), 28 significant tsunamis occurred in Martinique. The most significant events were those of 1 November in 1755 (Lisbon earthquake) and May 1902 (Mount Pelée eruptions). In the Caribbean, since 1850, tsunamis have killed at least 3500 people (Proenza and Maul, 2010). The French Geological and Mining Survey (BRGM) carried out preliminary studies in order to characterize this hazard in the Caribbean. Based on several potential tsunamigenic sources and by means of numerical simulations, the BRGM determined a tsunami travel time (TTT) and maximum amplitude of water for Guadeloupe and Martinique islands (Pedreros et al., 2007; Poisson and Pedreros, 2007). Of the five seismic scenarios proposed, four could impact Martinique in less than $36 \mathrm{~min}$ (Fig. 1) which gives very short time to manage a massive evacuation of the population.

In order to anticipate and optimize these evacuations, authorities should develop a local crisis plan to address the following issues: how many people are there to evacuate? How should the evacuation proceed? Where are the evacuation

\footnotetext{
${ }^{1}$ National Geophysical Data Center/World Data Service for Geophysics (NGDC/WDS): the global historical tsunami database consists of files containing information on tsunami events from 2000 B.C. to the present in the Atlantic, Indian, and Pacific Oceans; and the Mediterranean and Caribbean Seas (available at: http://www.ngdc.noaa.gov/hazard/tsu_db.shtml).
} 


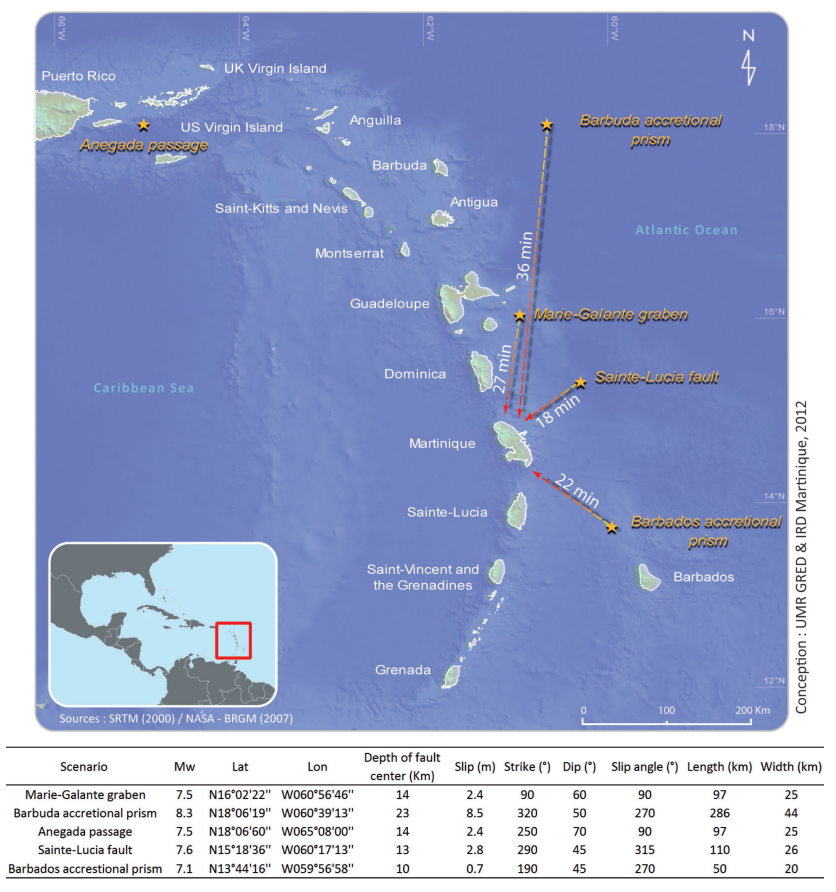

Fig. 1. Tsunamigenic seismic sources with expected arrival time of the first wave that could affect Martinique based on the models proposed by BRGM (Poisson and Pedreros, 2007).

sites? Where are the most efficient evacuation routes? How long does it take to evacuate them? To answer these essential questions, we propose in this paper an accessibility model of safety zones. This model was developed within the framework of CARIBSAT project (Caribbean Environmental Satellite Information System) managed by the Institute of Research for Development (IRD - Martinique) and cofinanced by European Union. This model follows a methodological framework transposable to various sites and represents a decision support tool useful for the authorities in charge of the evacuation process.

\subsection{Brief overview of tsunami evacuation modelling}

Different pedestrian evacuation models are available, depending on spatial scale and variables taken into account. These models are divided into two main categories: microscopic and macroscopic. Microscopic models simulate human behaviors incorporating several individual characteristics associated to virtual entities and the interactions between individuals usually at a small spatial scale. On the other hand, macroscopic models are based on aggregation levels on a large scale with the objective to understand the system as a whole and not just its components. Some studies have shown that important theoretical values (time, capacities, evacuation speed average, etc.) can be obtained in a particular zonal distribution (Boulanger and Bréchet, 2003; Hamacher and Tjandra, 2001). In risk management fields, micro-simulation models (social force model, agent based and cellular automata) are mainly developed for modelling evacuation of buildings (malls, resorts, stadiums...) (Fang et al., 2011; Valentin et al., 2011), cruise ship (Klüpfel et al., 2001) or train (Klügl et al., 2009). These tools have been used recently in modelling evacuation at the scale of the beach in a sub communal level (Sahal et al,, 2013), at the village level (e.g. Japan) (Mas et al., 2012), or at the scale of the city (e.g. Indonesia) (Lämmel et al., 2010; Taubenböck et al., 2009) in case of tsunami. Most of these tools require a thorough knowledge of computer programming and long term computation. Yet, integration of these results in a geographic information system (GIS) is limited. Our method is based on the use of a shortest path-based model, commonly called an "All-Or-Nothing" traffic assignment (Ramming, 2002) which is less realistic than a time-expanded network but is easier to solve and to implement (Lim et al., 2012; Hamacher and Tjandra, 2001). This network analysis tool was originally designed for the calculation of road itineraries. Its use has been diverted to calculate evacuation time and optimized route to ensure safety of people on foot in case of a tsunami. Similar approaches have been developed in tsunami risk assessment, especially in Indonesia to help for evacuation routes planning (González-Riancho et al., 2013; Dewi, 2010; Mück, 2008).

Our model will be extended by simulating several scenarios while adjusting different parameters such as refuge area's availability and evacuation route safety which take into account the possible obstructions and different travel speeds by elderly, children, disabled people, among others.

\subsection{Objectives}

The issue of territorial accessibility in connection with crisis management can be analyzed according to the different phases of a crisis: pre-crisis (evacuation) or post-crisis (access to emergency needs and other resources). In case of planned evacuations, an accessibility model provides the following solutions (Leone et al., 2013):

- Measuring the access time along the shortest routes between hazard zones and refuge areas;

- Estimating the number of evacuees using accessibility curves according to the time, which allows us to estimate the number of people to be saved prior to the arrival of the tsunami;

- Automatic selection of the evacuation sites and most relevant itineraries, based on the best pair time/distance route and the number of people who converge there.

\subsection{Working hypotheses}

Presently, there is no existing official tsunami hazard zone in Martinique. Based on historical tsunami run-up values in 
catalogues (Accary and Roger, 2010; Lander et al., 2002; Zahibo and Pelinovsky, 2001) and recent modelling of the amplitudes close to the coast (Harbitz et al., 2012; Roger et al., 2010; Le Friant et al., 2008; Poisson and Pedreros, 2007), we assume a maximum height of flooding up to $10 \mathrm{~m}$ above sea level (a.s.l.) for a seismic event. We consider that people who are living in areas below this altitude are exposed to tsunami and should be evacuated to safety zone at least above $20 \mathrm{~m}$ a.s.l. during an event.

The travel speeds used in our model have been defined for pedestrian evacuation in accordance with recommendations established by Unesco (IOC UNESCO, 2008). Pedestrian travel is more efficient in case of a quick evacuation within short period of time (Bolton, 2007). The compliance with this instruction limits the risk of traffic congestion on the routes. The experience of the 11 March 2011 tsunami in Japan has also shown that mortality rates were higher in areas where the population had not complied with this instruction (Fraser et al., 2012).

As for all patterns of macro-simulation, heterogeneousness of situations (people location, activity) had not been taking into account. We assume that people are informed and prepared and would try to reach the nearest designated evacuation sites through proper evacuation routes as fast as possible. Nevertheless, this last point needs to be validated by back analysis of future evacuation even though this behaviour seems logical.

The aim of our work is to provide several evacuation sites which offer safe short-term stay for the evacuees in collaboration with the local authorities. They should be accessed in less than 15 minutes on foot from the most distant exposed areas. This maximum delay is important to immediately ensure the safety of the population in case of a local or a regional tsunami which are possible scenarios suggested by BRGM in 2007 . We also indicate the optimal evacuation routes in terms of security, access time, travel distance and suitability in terms of the routes' capacities to facilitate the evacuation of the expected number of evacuees. Our method assesses modalities and feasibility of such an evacuation which is likely to occur in Martinique in the future.

\subsection{Modelling tool}

Accessibility calculations were performed using RouteFinder $^{\circledR}$ application in a GIS interface (MapInfo ${ }^{\circledR}$ ). The software selects the shortest paths in time or distance between several points of departure and arrival. The origin/destination matrix generated is mapped using isochronous and optimal routes. These shortest routes are determined according to the graph's theory which uses the Dijkstra's algorithm (Dijkstra, 1959). This application requires creation and configuration of the following GIS datasets as input:

- Starting points: grid of $50 \mathrm{~m}$ per side located less than 10 m a.s.l.;
- Exposed territory with aggregated population: number of residents during the night;

- A graph of routes;

- Arrival points: entry points to safety zones (EPSZ), i.e. the intersection between the $20 \mathrm{~m}$ contour line and the road network;

- Pedestrian travel speeds $\left(\mathrm{m} \mathrm{s}^{-1}\right)$ variable according to the type of route (width, surface condition, and slope).

\subsection{GIS database}

The resident population data were extracted from land ownership files of French Public Finances (DGFiP) and demographic data collected by the last general population census in 2006. The data provided by the DGFiP offer information about the use of space in the buildings (residential, professional or mixed) and the number of households per building. With these data, we were able to estimate for each cadastral plot the average number of occupants at night. Then, these numbers were aggregated on a grid of $50 \mathrm{~m}$ per side which represents the starting points of the model. For the whole of Martinique, 66377 persons are located at less than $10 \mathrm{~m}$ a.s.l. at night time.

The network communication routes from the $\mathrm{BD}$ TOPO ${ }^{\circledR}$ $(\mathrm{IGN}, 2004)^{2}$ were used to build the graph. The results of the accessibility model depend on the accuracy of the road graph. Very few errors were detected in this database. The portion of the network used (between 0 and $20 \mathrm{~m}$ a.s.l.) forms 61600 sections for a total length of $1625 \mathrm{~km}$. We were able to identify several types of paths: two-lane roads suitable for motor-vehicles, one lane roads, and earth roads (trails, track). This network has been updated and expanded for two municipalities to make the future modelling results more adapted to the present practice of the people. The improvements on the graph are based on high resolution airphoto-interpretation coming from BD ORTHO ${ }^{\circledR}$ (IGN, 2010) ${ }^{3}$ and field surveys.

Evacuation sites were identified automatically by overlapping network communication routes with the $20 \mathrm{~m}$ contour line extracted from a $1 \mathrm{~m}$ resolution digital elevation model (DEM) called Litto3D ${ }^{\circledR}$ (IGN, 2010) ${ }^{4}$. We did not consider the evacuation sites as such, but the entry points to safety zones. This topographic refuge zones generally offer large

\footnotetext{
${ }^{2}$ The BD TOPO $^{\circledR}$ from the French National Geographic Institute (IGN) is a 3-D vector description of territorial elements and infrastructures at metric scale. It is the topographic component of geographic Large Scale Reference (LSR).

${ }^{3}$ The BD ORTHO ${ }^{\circledR}$ from the French National Geographic Institute (IGN) is a geographic reference of orthorectified and georeferenced aerial photographs at the departmental level.

${ }^{4}$ Litto3 $\mathrm{D}^{\circledR}$ is a continuous land-sea altimetric digital model of the coastal fringe of the French territory carried out jointly by the French Navy's Hydrographic Oceanographic Department (SHOM) and IGN.
} 
capacities with the sole exception for the small landlocked areas. Therefore, we have generated 3854 EPSZ for the whole Martinique.

\subsection{Determining and setting evacuation speeds}

Pedestrians' travel speeds were identified from available bibliographic references (Moussaïd, 2010; Laghi et al., 2007; Daamen, 2004; Lee et al., 2004, 2003; Fruin, 1971) and some in situ tests, taking into account the slope and the road type, but without consideration of the potential network congestion and the physical and psychological profile of people. These effects could be taken into account by a complementary method using a macro-simulation tool such as SimWalk ${ }^{\circledR}$, similar to what we have already done but at a limited scale (Sahal et al., 2013).

Without interaction with other people or physical obstacles from the environment, a "comfortable" pedestrian's speed is about $1.3 \mathrm{~m} \mathrm{~s}^{-1}$ (or approximately $5 \mathrm{~km} \mathrm{~h}^{-1}$ ) (Moussaïd, 2010). Nevertheless, we have indirectly incorporated the pedestrian density's effects on the traffic's flow using a friction coefficient. This factor was defined by means of a formula used by Dewi (2010) which relies on the width of the escape route and the surface type. In the case of stairs, an additional average value of $0.5 \mathrm{~m} \mathrm{~s}^{-1}$ is assumed, suggested by Fruin (1971). The network has been divided into 10 classes of slopes extracted from Litto3D with a range of $3 \%$. By combining these classes of slope and the three different types of street, we obtained 30 classes of specific speeds from $4.85 \mathrm{~km} \mathrm{~h}^{-1}\left(1.35 \mathrm{~m} \mathrm{~s}^{-1}\right)$ to $0.86 \mathrm{~km} \mathrm{~h}^{-1}\left(0.24 \mathrm{~m} \mathrm{~s}^{-1}\right)$. These travel speeds have been estimated for a healthy adult. Some areas of the evacuation zone are not accessible by roads. Therefore RouteFinder ${ }^{\circledR}$ tool generates a link to the nearest part of the network for which we set a theoretical walking speed at $1 \mathrm{~km} \mathrm{~h}^{-1}\left(0.28 \mathrm{~m} \mathrm{~s}^{-1}\right)$. This low value takes into account both possible natural and artificial obstacles along the routes. Our simulations were bound by a critical value of $30^{\circ}(58 \%)$ slope and above on which evacuation by foot is no longer possible. Based on existing data, no road section reaches this slope in Martinique.

\section{Results and discussion}

\subsection{Evacuation time limit vs. arrival time of a tsunami}

One of the most important information to consider in planning evacuation procedure is the theoretical arrival time of the first devastating waves. Confronted with tsunami scenarios, this information allows us to define the maximum time available for the evacuation of exposed populations and to identify critical areas which are far from evacuation sites (González-Riancho et al., 2013; Scheer et al., 2012).

The maximum evacuation times have been calculated for each municipality. They were also mapped on two areas namely Fort-de-France conurbation and Sainte-Anne munic-

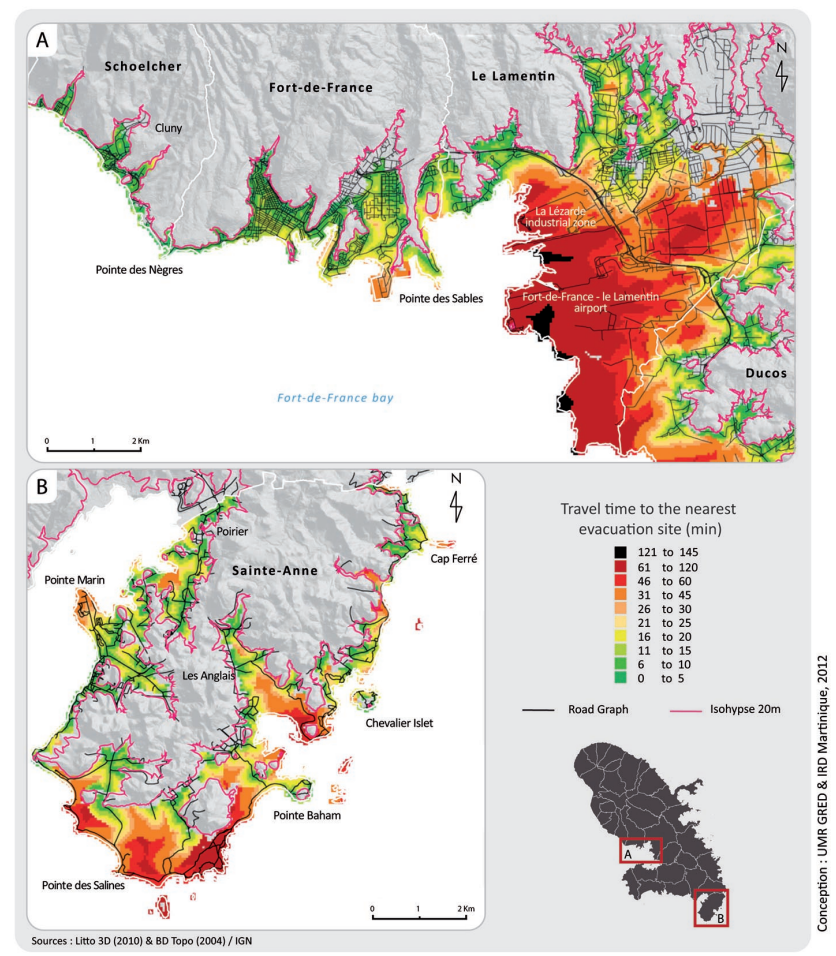

Fig. 2. Access time ( $\mathrm{min}$ ) to the closest evacuation site (20 m a.s.1.): the case of Fort-de-France conurbation (A) and the touristic municipality of Sainte-Anne (B).

ipality which have high human exposure (Fig. 2). These maps show the most remote areas in terms of travel time to the nearest topographic shelters (e.g. sectors of the Lamentin Airport and the Salines beach in Sainte-Anne). This result aims to raise stakeholder's awareness to define and open vertical shelters within the tsunami hazard zone which comply to standard restrictions (FEMA, 2009). Indeed, for responsibility reasons vertical shelters are not yet an option in our model. A seismic vulnerability assessment of existing building must be done. It is especially because Martinique is threatened by near field earthquake and ground shaking could affect the building infrastructures and their structural stability. In addition, agreements should be made with managers or building owners to ensure access points or to create special facilities (e.g. a roof access for evacuation). Finally, tsunami safety instructions have to be consistent with the existing ones such as the building evacuation procedure in case of seismic activities. Moreover, we are able to locate preferred implantation sites with respect to maximum evacuation time and to selected buildings in accordance to safety height, hydraulic resistance and probable damages by floating debris (Scheer et al., 2012).

Based on the resident population spatial database and the theoretically modelled evacuation time, we built an accessibility curve at the scale of Martinique Island. This curve corresponds to the needed time for the population to reach 


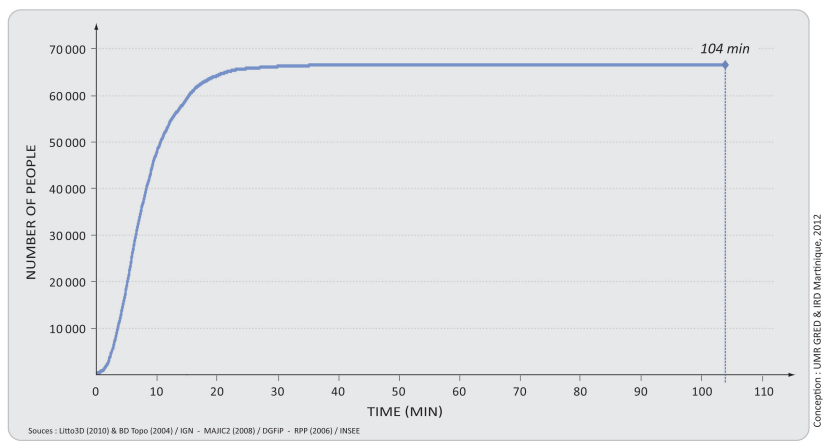

Fig. 3. Accessibility curve of safe zones for the whole Martinique (night population located under $10 \mathrm{~m}$ a.s.l., $20 \mathrm{~m}$ high shelter scenario).

a safety zone. It indicates $104 \mathrm{~min}$ as maximum theoretical time to ensure the safety of exposed population (less than 10 m a.s.1.) (Fig. 3). It appears that almost $90 \%$ of these populations could be evacuated within less than $16 \mathrm{~min}$. This analysis shows a great spatial heterogeneity. Generally, less time is required in the Northern municipalities of the Martinique. This feature is explained by the shorter distances to reach higher ground in coastal regions in the North. Thus, the curves rate varies depending on the efficiency of network communication and the proximity of refuge zones.

We also analyze the theoretical feasibility of evacuation by comparing the time to ensure the safety of people in several tsunami travel time scenarios. For example, the minimum time of arrival on the coast of Martinique particularly in Saint-Luce of a tsunami generated by an earthquake of $M_{\mathrm{w}}=7.1$ at the accretionary prism of Barbados was estimated at 22 min (Poisson and Pedreros, 2007). According to our model and considering a limited time of $15 \mathrm{~min}$ for the transmission of the warning (supposed to be guaranteed by the future regional warning system), $50.5 \%$ of the exposed population of Martinique could be protected in less than $7 \mathrm{~min}$ for this scenario. On the other hand, 33000 people would not have enough time to reach the designated evacuation sites. We notice that Fort-de-France, Lamentin and Robert are likely the most impacted municipalities with 8167,4656 and 3870 unsafe persons, respectively, at the time of the impact of the tsunami (Fig. 4). But these theoretical time limits do not consider the reaction time of populations which is very difficult to predict (Ishiwatari and Arakida, 2012).

\subsection{Aid for planning local evacuations}

This accessibility model enables us to automatically map optimized evacuation routes according to the best value for distance/travel time and to preselect the most relevant entry point to safety zone based on their load capacity (Fig. 5).

According to our method, the number of EPSZ requested by the model and their dispersion are dependent on the

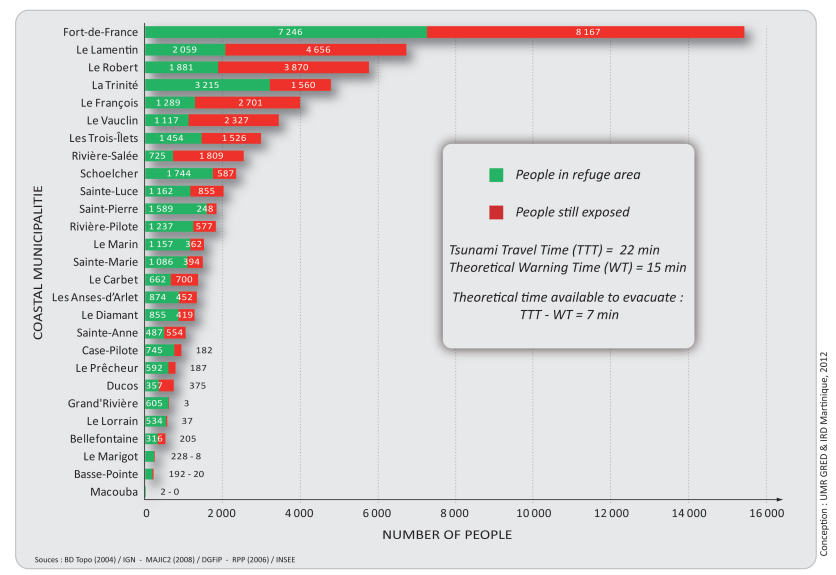

Fig. 4. Estimated number of people per municipality who could (green) or who could not (red) reach a safe zone in less than $7 \mathrm{~min}$ on foot in case of tsunami generated from Barbados accretional prism (night population located under $10 \mathrm{~m}$ a.s.1., $20 \mathrm{~m}$ high shelter scenario).

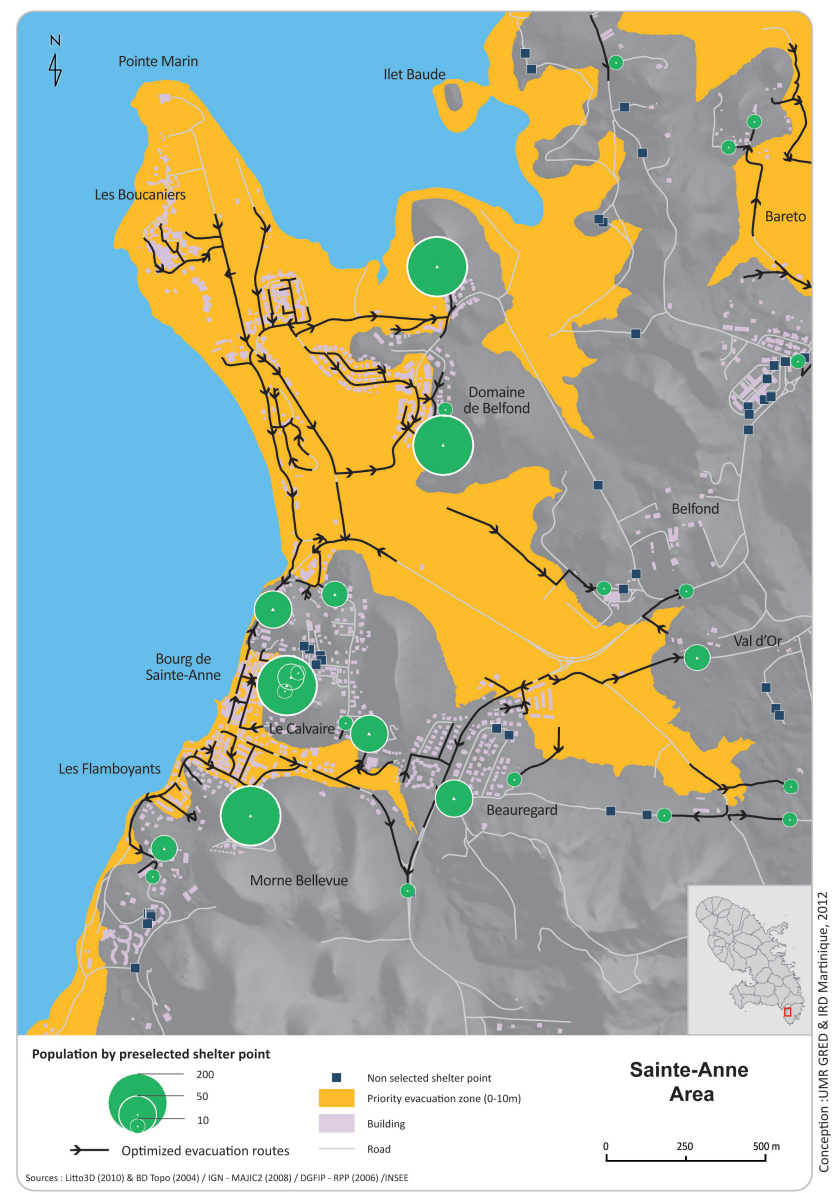

Fig. 5. Automatic preselection of safe sites ( $20 \mathrm{~m}$ high shelter) and optimal evacuation routes for populated areas (e.g. Sainte-Anne municipality). 
quality of the road network. For instance, in the area of SaintAnne municipality, the EPSZ distribution is heterogeneous. Only 27 out of 77 EPSZ automatically and previously generated could receive a minimal charge of 1 person during a "nocturnal" scenario. In addition, four points are especially requested. They covered an evacuation zone comprised by highly populated buildings and could receive more than 100 evacuees.

In addition to the road graph improvement, we propose classifications of evacuation sites from various criteria collected on the fieldwork such as: accessibility, capacity, availability, and safety. These criteria can be used to identify the best locations for evacuation. They are particularly useful in areas with multiple possible evacuation sites such as in the case of the village of Sainte-Anne where there are four EPSZ that are grouped together in the same area. This task will be done using photo-interpretation and field recognition. Additional modelling will quantify the number of theoretical passages cumulated by road sections, which may correspond to the maximum number of evacuees of the road network, the theoretical maximum expected load. These results will assess the potential effects of network congestion during an evacuation.

These mapping results provide many opportunities to develop or improve local planning of the operational response and preparedness at the local scale:

- Identify evacuation sites for the baseline scenario, depending on the altitude that are safe for the exposed population;

- Search for new evacuation sites to reduce evacuation time (for example, conversion of tall and resistant buildings to vertical shelters);

- Propose the locations of signpost along the preferred evacuation routes;

- Search for alternative routes to ensure smooth traffic flow during the evacuation process;

- Define the zone covered by each shelter point.

Many improvements, including an enhanced database, should be carried out for the entire island. They should be locally validated by a concerted fieldwork with emergency operators and local authorities in order to produce an official map-based evacuation plan. Future studies will be carried out on the spatial distribution of human activities and resources at different time frame. It is essential to take into account the strong seasonal and daily variations of tourist fluctuations. Thus, several evacuation scenarios can be implemented by modulating the number of population (day/night), the profiles of people (adults, children, and disabled), selected evacuation sites, warning time and response times of population, tsunami delay and penetration distance. The population census can be refined by counting in situ, especially on touristic sites and/or highly exposed areas like beaches. A model

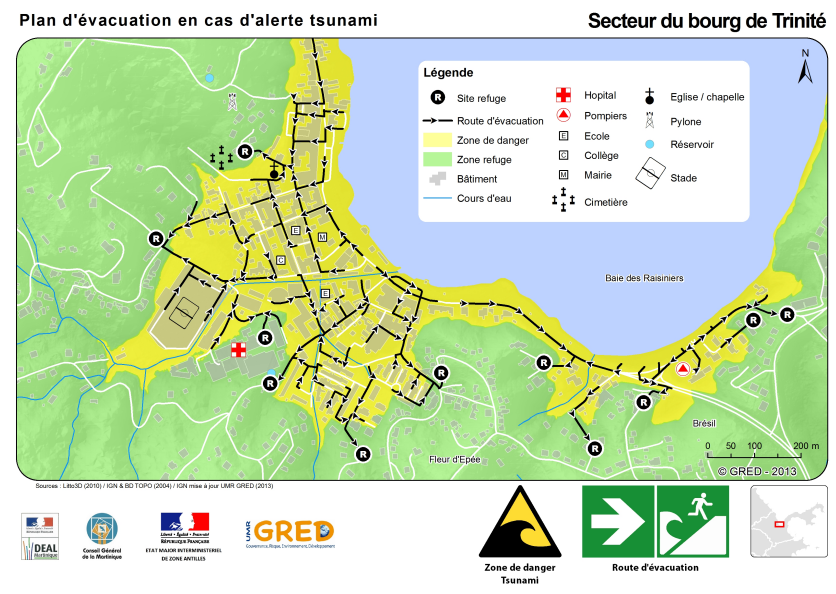

Fig. 6. Extract of evacuation map approved by the French Department of Civil Defense and Emergency Preparedness of Antilles Zone (EMIZA) (e.g. Trinité downtown).

dedicated to the evacuation of zones such as the beaches in Martinique is being completed. We are also working with local authorities to define safety criteria necessary to establish future evacuation routes and safe zones. We will especially take into account the buildings collapse probability, in case of near field seismic sources, or coastal and estuary proximity, which are tsunami-prone areas.

\section{Conclusion for a best crisis management}

The methodological framework used in this study and addressed to decision makers links the scientific practice (modelling of tsunamis, arrival times, wave heights...) and the crisis management field.

Even if the proposed scenario is probably conservative for the Martinique coasts, we were able to generate many useful maps and graphs to prepare and plan evacuation procedure for the population in case of a tsunami event. The advantages of the method include reproducibility and the adaptability to different scales of study as long as databases are available. On the other hand, the implementation of preventive measures facilitated by these models depends first and foremost on the degree of political involvement to display the risk without damaging the idyllic image of these touristic places. The Lesser Antilles French territories are still far behind these issues and have no specific local plan in response to this threat. The areas of the Lesser Antilles, such as Antigua and Barbuda, Trinidad and Tobago and the British Virgin Islands already have evacuation plans and are installation of information and warning signage about the risk of tsunami. The island of Anguilla and 22 cities in Puerto Rico have acquired the recognition "Tsunami Ready Communities" by the US National Weather Service of NOAA (National Oceanic and Atmospheric Administration). Since 2006, the safety precaution is accompanied by a regional consultation uniting 38 
countries members of the Caribbean Basin. These efforts are under the auspices of the Intergovernmental Oceanographic Commission of Unesco (ICG/CARIBE EWS ${ }^{5}$ ) with a view to establish local tsunami warning systems.

The method proposed in this study has been improved for two pilot municipalities of Martinique (Trinité and SainteAnne). The operational capability of the method and its results were validated through a participatory field survey in collaboration with local partners which include the public sector services and local authorities. The results of the model were used as decisional supports in choosing the evacuation sites and routes. The entire validation chain was supervised at three crisis management levels (French Department of Civil Defense and Emergency Preparedness of Antilles Zone, Martinique prefecture civil protection services, municipalities' population safety and protection services). This validation effort has led to the production of evacuation reference maps for both pilot municipalities (Fig. 6).

These operational results were presented to a larger audience during the annual week of seismic awareness campaign named "REPLIK" ("Aftershock" in French) on 12 November 2013 (Audru et al., 2013). This presentation was an opportunity to unveil ISO tsunami signage on the first evacuation route optimized by this method.

Acknowledgements. This work was carried out within the framework of the project CARIBSAT (INTERREG IV Caribbean) co-financed by the European Commission and managed by the Institute of Research for Development (IRD). A full report is available on the project's website - www.caribsat.fr. This work is ongoing with the support of the Fondation de France in view of the project "What coastlines for tomorrow?" (Project No. 1204), in collaboration with the French Department of Civil Defense and Emergency Preparedness of Antilles Zone (EMIZA). The authors express their gratitude to Hélène Hebert, Julie Morin and Jake Cadag for their constructive comments given during the preparation of this paper and to Brigitte Lalagüe and Keith Taylor for reviewing the English.

Edited by: J. Roger

Reviewed by: G. Lämmel and one anonymous referee

\section{References}

Accary, F. and Roger J.: Tsunami catalog and vulnerability of Martinique (Lesser Antilles, France), Sci. Tsunami Haz., 29, 148174, 2010.

Audru, J. C., Vernier, J. L., Capdeville, B., Salindre, J. J., and Mouly, É.: Preparedness actions towards seismic risk mitigation for the general public in Martinique, French Lesser Antilles: a mid-term appraisal, Nat. Hazards Earth Syst. Sci., 13, 20312039, doi:10.5194/nhess-13-2031-2013, 2013.

${ }^{5}$ ICG/CARIBE EWS: Intergovernmental Coordination Group for Tsunami and other Coastal Hazards Warning System for the Caribbean and Adjacent Regions
Bolton, P. A.: Managing Pedestrians during Evacuations of Metropolitan Areas, U. Department of Transportation Federal Highway Administration, 91 p., 2007.

Boulanger, P. M. and Bréchet, T.: Une analyse comparative des classes de modèles " Modélisation et aide à la décision pour un développement durable”, Action de support PADD I, SST, p. 32, 2003.

IOC UNESCO: Tsunami preparedness - Information guide for disaster planners, Manuals and Guides No. 49, Paris, UNESCO, p. 29, 2008.

Daamen, W.: Modeling Passenger Flows in Public Transport Facilities, Delft University of Technology, p. 403, 2004.

Dewi, R. S.: A GIS-based approach to the selection of evacuation shelter building and routes for tsunami risk reduction, A case study of Cilacap coastal area Indonesia, Double Degree International Programme of Geo-Information for Spatial Planning and Risk Management, University of Twente (Netherlands) and Gadjah Mada University (Indonesia), p. 166, 2010.

Dijkstra, E. W.: A note on two problems in connexion with graphs, Num. Mathe., 1, 269-271, 1959.

Fang, Z., Li, Q., Han, L. D., and Wang, D.,: A proposed pedestrian waiting-time model for improving space-time use efficiency in stadium evacuation scenarios, Build. Environ. 46, 1774-1784, 2011.

FEMA (Federal Emergency Management Agency): Vertical Evacuation from Tsunamis: A Guide for Community Officials, Repport P646A, p. 58, 2009.

Fraser, S., Leonard, G. S., Matsuo, I., and Murakami, H.: Tsunami evacuation: Lessons from the Great East Japan earthquake and tsunami of 11 March 2011, GNS Science Report 2012/17, p. 89, 2012.

Fruin, J.: Pedestrian Planning and Design, Metropolitan Association of Urban Design and Environmental Planners, Inc., New York, 20, p. 6, 1971.

González-Riancho, P., Aguirre-Ayerbe, I., Aniel-Quiroga, I., Abad, S., González, M., Larreynaga, J., Gavidia, F., Gutiérrez, O. Q., Álvarez-Gómez, J. A., and Medina, R.: Tsunami evacuation modelling as a tool for risk management: application to the coastal area of El Salvador, Nat. Hazards Earth Syst. Sci. Discuss., 1, 2163-2205, doi:10.5194/nhessd-1-2163-2013, 2013.

Hamacher, H. W. and Tjandra, S. A.: Mathematical Modelling of Evacuation Problems: A State of Art, Berichte des Fraunhofer ITWM, Nr. 24, p. 45, 2001.

Harbitz, C. B., Glimsdal, S., Bazin, S., Zamora, N., Løvholt, F., Bungum, H., Smebye, H., Gauer, P., and Kjekstad, O.: Tsunami hazard in the Caribbean: Regional exposure derived from credible worst case scenarios, Continental Shelf Res., 38, 1-23., 2012.

Ishiwatari, M. and Arakida, M.: Evacuation, Knowledge Note 26 cluster 2: Nonstructural Measures, The World Bank Intitute, p. 16, 2012.

Klügl, F., Klubertanz, G., and Rindsfüser, G.: Agent-based pedestrian simulation of train evacuation integrating environmental data, Adv. Artif. Intell., 5803, 631-638, 2009.

Klüpfel, H., Meyer-König, T., Wahle, J., and Schreckenberg, M.,: Microscopic simulation of evacuation processes on passenger ships, Theory and practical issues on cellular automata, Springer London, 63-71, 2001.

Laghi, M., Cavalleti, A., and Polo, P.: Evacuation routes tools ArcGIS Toolbox, Asian Disaster Preparedness Center, p. 98, 2007. 
Lander, J. F., Whiteside, L. S., and Lockridge, P. A.: A brief history of tsunamis in the Caribbean sea, Science of Tsunami Hazards, 20, 57-94, 2002.

Lämmel, G., Grether, D., and Nagel, K.: The representation and implementation of time-dependent inundation in large-scale microscopic evacuation simulations, Trans. Res. C, 18, 84-98, 2010.

Lee, D., Kim, H., Park, J. H., and Park, B. J.: The current status and future issues in human evacuation from ships, Safe. Sci., 41, 861-876, 2003.

Lee, D., Park, J.-H., and Kim, H.: A study on experiment of human behavior for evacuation simulation, Ocean Eng., 31, 931-941, 2004.

Le Friant, A., Heinrich, P., and Boudon, G.: Field survey and numerical simulation of the 21 November 2004 tsunami at Les Saintes (Lesser Antilles), Geophys. Res. Lett., 35, L12308, doi:10.1029/2008GL034051, 2008.

Leone, F., Péroche, M., Lagahé, E., Gherardi, M., Sahal, A., Vinet, F., Hachim, S., and Lavigne, F.: Modélisation de l'accessibilité territoriale pour l'aide à la gestion de crise tsunami (Mayotte, France), Annales de Géographie, Ed. A. Colin, Paris, No. 693, 502-524, 2013.

Lim, G. J., Zangeneh, S., Baharnemati, M. R., and Assavapokee, T.: A capacitated network flow optimisation approach for short notice evacuation planning, Eur. J. Operational Res., 223, 234245, 2012.

Mas, E., Suppasri, A., Imamura, F., and Koshimura, S.: Agent-based Simulation of the 2011 Great East Japan Earthquake/Tsunami Evacuation: An Integrated Model of Tsunami Inundation and Evacuation, J. Nat. Disaster Sci., 34, 41-57, 2012.

Mück, M.: Tsunami Evacuation Modelling. Development and application of a spatial information system supporting tsunami evacuation planning in South- West Bali.- Diploma Thesis, German Remote Sensing Data Center (DFD), Oberpfaffenhofen, 131 pp., 2008.

Moussaïd, M.: Étude expérimentale et modélisation des déplacements collectifs de piétons, Thèse de doctorat, Université Toulouse II - Paul Sabatier, p. 225, 2010.
Pedreros, R., Terrier, M., and Poisson, B.: Tsunamis: étude de cas au niveau de la côte antillaise française, Rapport de synthèse BRGM/RP 55795, Orléans, p. 77, 2007.

Poisson, B. and Pedreros, R.: Tsunamis: étude de cas au niveau de la côte antillaise française - Modélisation numérique, Rapport BRGM/RP 55761, Orléans, p. 111, 2007.

Proenza, X. and Maul, A.: Tsunami hazard and total risk in the Caribbean basin, Sci. Tsunami Haz., 29, 70-77, 2010.

Ramming, M. S.: Network Knowledge and Route Choise, Ph.D. Thesis, Massachusetts Institute of Technology, p. 394, 2002.

Roger, J., Baptista, M. A., Sahal, A., Accary, F., Allgeyer, S., and Hebert, H.: The Transoceanic 1755 Lisbon Tsunami in Martinique, Pure Appl. Geophys., 168, 1015-1031, 2010.

Sahal, A., Leone, F., and Péroche, M.: Complementary methods to plan pedestrian evacuation of the French Riviera's beaches in case of tsunami threat: graph- and multi-agentbased modelling, Nat. Hazards Earth Syst. Sci., 13, 1735-1743, doi:10.5194/nhess-13-1735-2013, 2013.

Scheer, S. J., Varela, V., and Eftychidis, G.: A generic framework for tsunami evacuation planning, Phys. Chem. Earth, Parts A/B/C, 49, 79-91, 2012.

Taubenböck, H., Goseberg, N., Setiadi, N., Lämmel, G., Moder, F., Oczipka, M., Klüpfel, H., Wahl, R., Schlurmann, T., Strunz, G., Birkmann, J., Nagel, K., Siegert, F., Lehmann, F., Dech, S., Gress, A., and Klein, R.: "Last-Mile" preparation for a potential disaster - Interdisciplinary approach towards tsunami early warning and an evacuation information system for the coastal city of Padang, Indonesia, Nat. Hazards Earth Syst. Sci., 9, 15091528, doi:10.5194/nhess-9-1509-2009, 2009.

Valentin, J., Coudret, F., Gouardères, E., and Lefer, W.: Modélisation du comportement humain pour la simulation d'évacuation de bâtiment en feu, Revue Electronique Francophone d'Informatique Graphique (REFIG) 5, 41-51, 2011.

Zahibo, N. and Pelinovsky, E. N.: Evaluation of tsunami risk in the Lesser Antilles, Nat. Hazards Earth Syst. Sci., 1, 221-231, doi:10.5194/nhess-1-221-2001, 2001. 